\title{
Comparação de métodos de enxertia em pepino.
}

\author{
Kathia Alexandra L. Canizares; Rumy Goto \\ UNESP-FCA, C. Postal 237, 18.603-970 Botucatu - SP, E-mail: kalcaniza@hotmail.com
}

\section{RESUMO}

Foram comparados três métodos de enxertia sobre o crescimento, floração e produção de pepino (Cucumis sativus L.), híbrido Hokuho enxertado em abóbora (Cucurbita maxima Duch.), hibrido Excite Ikky. $\mathrm{O}$ ensaio foi instalado em ambiente protegido na UNESP-FCA em Botucatu. Plantas enxertadas por fenda, encostia e perfuração apical foram comparadas com plantas não enxertadas. As características avaliadas foram sobrevivência de mudas, altura da planta, número de internódios, diâmetro do hipocótilo, número de dias até a floração, número de flores femininas e masculinas, número de dias até o inicio da colheita, número de frutos abortados e comerciáveis/planta em cinco semanas de colheita. O delineamento experimental foi de blocos ao acaso, com cinco repetições e dois vasos por parcela. As plantas não enxertadas apresentaram maior porcentagem de sobrevivência. A enxertia por qualquer método não influenciou na altura das plantas, mas o número de internódios foi superior nas plantas enxertadas por fenda. O diâmetro do hipocótilo e o número de frutos abortados foi maior nas plantas enxertadas. A enxertia não modificou a expressão sexual nem a produção de frutos comerciáveis/planta. Foi observada a presença de brilho na casca de todos os frutos colhidos de plantas enxertadas.

\begin{abstract}
Comparison of grafting methods in cucumber.

A trial was carried out under protected cultivation to compare three grafting methods on growth, flowering and yield of cucumber (Cucumis sativus L.), hybrid Hokuho grafted on squash (Cucurbita maxima Duch.), hybrid Excite Ikky, at UNESP in Botucatu, Brazil. Plants were grafted by cleft, approach and tongue grafting, and compared with cucumber plants without grafting. Seedling survival, plant height, node number, hypocotyl diameter, days to flowering, number of female and male flowers, days to first harvest, number of aborted fruits, and commercial fruits per plant during five weeks were evaluated. The trial was carried out in a randomized complete block design, with five replications and two plants per plot. The greatest survival rate was obtained from non-grafted plants. Grafting methods had no influence on plant height, however, node number was greater in cleft grafted plants. Hypocotyl diameter and number of fruits which failed to set were greater in grafted plants than in non grafted ones. Grafting did not affect sex expression and commercial fruit yield per plant. Fruits harvested from grafted plants were shiny.
\end{abstract}

Keywords: Cucumis sativus L., Cucurbita maxima, grafting, protected cultivation.
Palavras-chave: Cucumis sativus L., Cucurbita maxima, enxertia, ambiente protegido.

(Aceito para publicação em 16 de janeiro de 2.002)

$\mathrm{N}_{\mathrm{b}}$ cultivo de cucurbitáceas em ambiente protegido, a enxertia pode ser considerada atualmente como método alternativo de produção. Com este método visa-se a menor incidência de doenças fúngicas do solo, menor infestação de nematóides e melhoria da qualidade dos frutos com a retirada da cera, resultando em maior brilho (Canizares et al., 1996).

Os patógenos do solo, incluindo nematóides, são responsáveis por $67,7 \%$ dos replantios necessários em hortaliças (Oda, 1995). Outros patógenos são responsáveis por $23,7 \%$, pragas por $1,2 \%$, desordens fisiológicos $5,3 \%$, desbalanço nutricional do solo $0,3 \%$ e causas desconhecidas $1,8 \%$.

Além desse aspecto, algumas combinações enxerto/porta-enxerto têm sido relacionadas não só com a resistência do porta-enxerto a fatores adversos, mas também ao aumento da produção (Yamakawa, 1982; Kawaide, 1985; Cañizares, 1997) tendo em vista que determinados porta-enxertos induzem o aumento do vigor da copa (Janowski \& Skapski, 1985).

O sucesso da enxertia é representado pela união morfológica e fisiológica das duas partes envolvidas. Miguel (1997) observou que as superfícies de contato do enxerto e porta-enxerto devem estar limpas. Mesmo que haja boa cicatrização na região da enxertia, se houver pouco contato, esta pode dificultar o movimento da água e dos nutrientes. Dessa forma, os elementos vasculares não iniciam a atividade do câmbio vascular e a enxertia tende a fracassar (Deloire \& Hébant, 1982 citados por Rachow-Brandt \& Kollmann, 1992b), por interferir na translocação de assimilados da raiz para a parte aérea da planta (Andrews \& Marquez, s/d; Rachow-Brandt \& Kollmann, 1992a), e também por alterar a concentração de alguns elementos nutritivos. Alguns fatores interferem no sucesso da enxertia, como por exemplo a temperatura na pós- enxertia influenciando a sobrevivência das plântulas. É recomendado manter os enxertos entre 25 e $26^{\circ} \mathrm{C}$ durante a fase de união. Temperaturas inferiores a 15 ou superiores a $32^{\circ} \mathrm{C}$ são prejudiciais (Miguel, 1997). Stripari et al. (1997) com $30^{\circ} \mathrm{C}$ na pós-enxertia, obtiveram entre 96,5 e $100,0 \%$ de sobrevivência de plântulas enxertadas, aos 25 dias pós enxertia, em pepino híbrido Summer Green enxertado em abóbora híbrida Kirameki usando o método da fenda cheia. A umidade também interfere e esta deve ser mantida elevada para evitar a desidratação dos tecidos. Afetam também a enxertia a diferença entre os diâmetros do hipocótilo do enxerto e do porta-enxerto (Stripari et al., 1997). No Japão, Oda et al. (1993), avaliando a taxa de sobrevivência e o crescimento de plantas de pepino, utilizando a enxertia horizontal em dois porta-enxertos, (Cucurbita moschata e C. maxima), concluíram que com a menor diferença entre o diâmetro do hipocótilo do en- 
xerto e porta-enxerto, a taxa de crescimento e sobrevivência aumentava.

A sobrevivência da enxertia depende também da remoção ou não das folhas cotiledonares e do ângulo de sobreposição das folhas cotiledonares. Oda et al. (1993) concluíram que a taxa de sobrevivência dos enxertos de pepino sobre abóbora sem cotilédones no porta-enxerto foi significativamente menor $(75 \%)$ que as que continham cotilédones (maior que 90\%). Nos enxertos com $90^{\circ}$ de ângulo formado entre os cotilédones de porta-enxerto e enxerto, a taxa de sobrevivência foi $100 \%$, comparado com $50 \%$ em enxertos com $0^{\circ}$ de ângulo.

$\mathrm{Na}$ prática têm sido utilizadas enxertias por fenda, encostia e perfuração apical. Os produtores paulistas de pepino japonês têm muitas dúvidas em relação às alterações que as plantas enxertadas apresentam, afirmando que o desenvolvimento da planta enxertada varia em função do método empregado. Desse forma esse experimento teve por objetivo comparar três métodos de enxertia na sobrevivência das mudas, crescimento, floração e na produção de pepino do tipo japonês.

\section{MATERIAL E MÉTODOS}

O experimento foi conduzido em estruturas de proteção com cobertura plástica $(7,0 \times 20,0 \mathrm{~m})$, na área experimental da Fazenda Lageado, do Depto. de Produção Vegetal da UNESP em Botucatu, de fevereiro a junho de 1998. Foram realizados quatro tratamentos, três métodos de enxertia e o controle sem enxertia. $\mathrm{O}$ delineamento experimental utilizado foi blocos ao acaso, com 4 tratamentos e 5 repetições com 2 plantas/parcela (1 planta/vaso), exceto para a sobrevivência das mudas (50 plantas/parcela).

A abóbora foi semeada em 25/02 e o pepino em 27/02. A enxertia foi feita em 12/03 (25 enxertos por parcela), seguindo os critérios de Kawaide (1985); Oda (1995) e Miguel (1997).

Em todos métodos de enxertia o meristema apical da abóbora foi eliminado, deixando-se apenas as duas folhas cotiledonares. Em todos métodos, os cotilédones do pepino foram

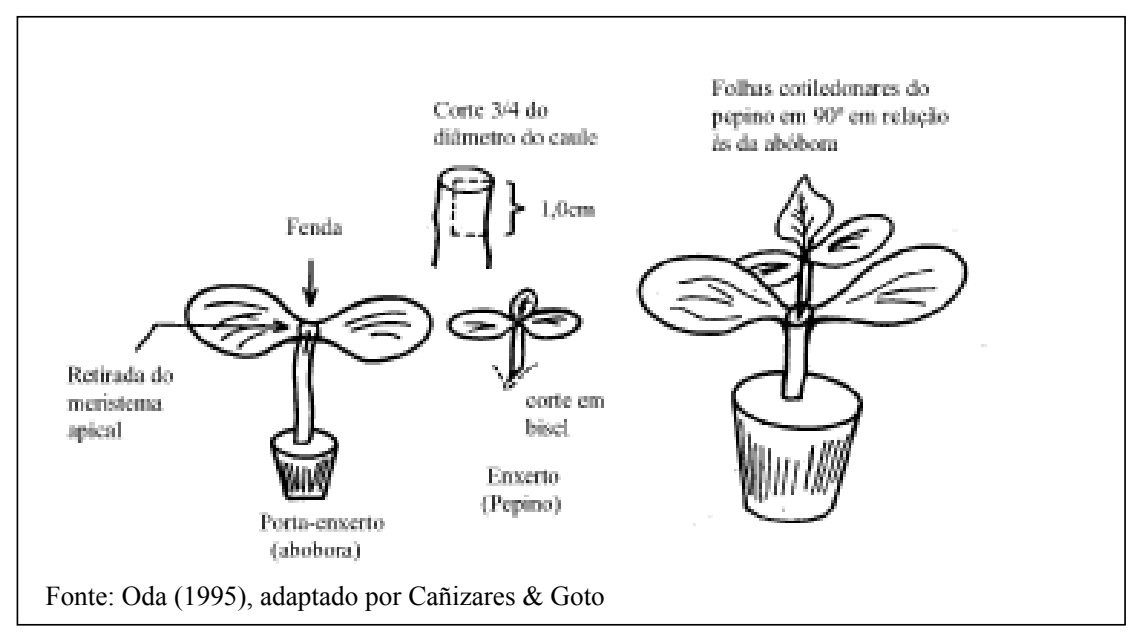

Figura 1. Enxertia por garfagem de fenda cheia.

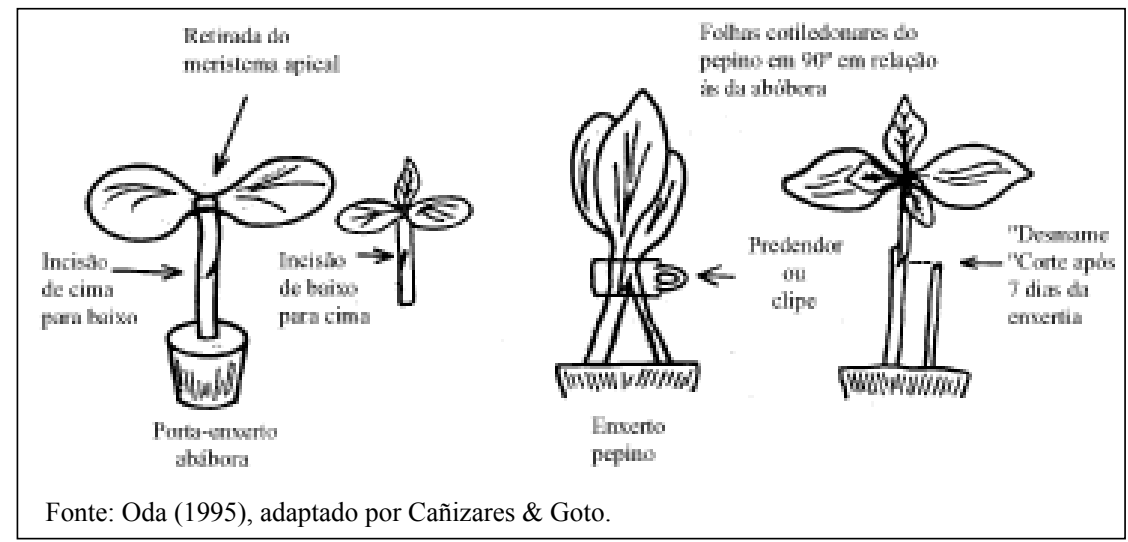

Figura 2. Enxertia por encostia.

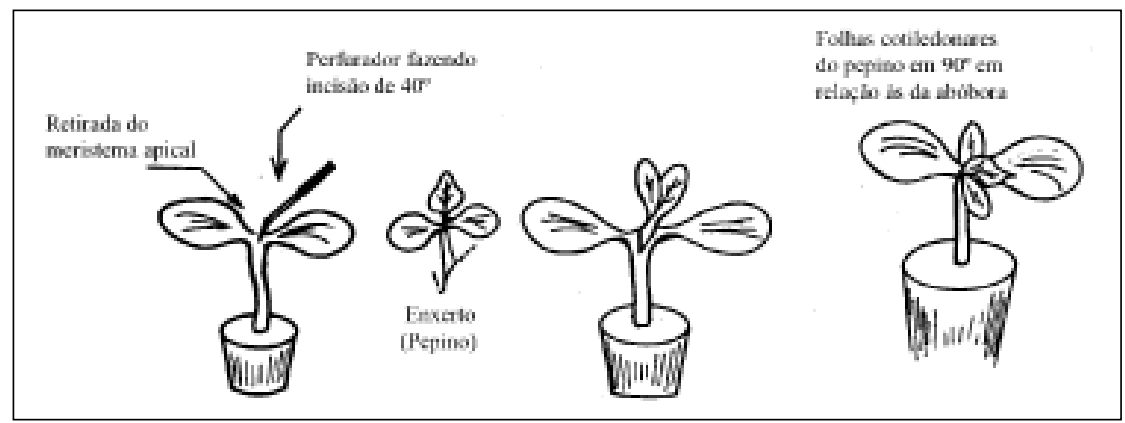

Figura 3. Enxertia por perfuração apical.

posicionadas a $90^{\circ}$ em relação aos cotilédones da abóbora (Figura 1), conforme Oda et al. (1993).

No método de garfagem de fenda cheia foi feito um corte de mais ou menos $1,0 \mathrm{~cm}$ de profundidade entre os cotilédones da abóbora, até o centro do hipocótilo (Figura 1). O hipocótilo do pepino foi cortado em forma de bisel a $1,5 \mathrm{~cm}$ abaixo dos cotilédones e inserido na fenda. Enxerto e porta-enxerto foram presos por um clipe especial.
No método por encostia, foi feito um corte de cima para baixo, $1,0 \mathrm{~cm}$ abaixo das folhas cotiledonares da abóbora (Figura 2). Nas plântulas de pepino, com o sistema radicular, o corte foi feito de baixo para cima. Feita a união, o enxerto foi preso por um clipe especial. Seis dias após a enxertia promoveu-se o 'desmame', que consistiu em cortar o hipocótilo do pepino logo abaixo do ponto de enxertia para isolar o sistema radicular do mesmo. 
Tabela 1. Sobrevivência das plântulas (SP), altura das plantas (AP), número de internódios (NI), diâmetro do hipocótilo (DH) e número de dias para floração (DF) para plantas de pepino com e sem enxertia, usando os métodos de fenda cheia, encostia e perfuração apical. Botucatu, UNESP, 1998.

\begin{tabular}{lccccc}
\hline \multicolumn{1}{c}{ Tratamento } & $\mathbf{S P}^{* *}(\%)$ & $\mathbf{A P}(\mathbf{c m})$ & $\mathbf{N I}^{*}(\mathbf{n} \mathbf{0} / \mathbf{p l})$ & $\mathbf{D H}^{* *}(\mathbf{c m})$ & $\mathbf{D F}$ (dias) \\
\hline Fenda cheia & $88,0 \mathrm{ab}$ & $133,0 \mathrm{a}$ & $19,6 \mathrm{a}$ & $1,5 \mathrm{a}$ & $24,2 \mathrm{a}$ \\
Encostia & $72,0 \mathrm{~b}$ & $128,4 \mathrm{a}$ & $18,5 \mathrm{ab}$ & $1,6 \mathrm{a}$ & $23,0 \mathrm{a}$ \\
Perfur. apical & $68,0 \mathrm{c}$ & $123,0 \mathrm{a}$ & $18,4 \mathrm{~b}$ & $1,4 \mathrm{a}$ & $25,0 \mathrm{a}$ \\
Pé franco & $94,0 \mathrm{a}$ & $125,0 \mathrm{a}$ & $18,3 \mathrm{~b}$ & $1,1 \mathrm{~b}$ & $24,8 \mathrm{a}$ \\
Média & 80,5 & 127,4 & 18,7 & 1,4 & 24,2 \\
\hline CV $(\%)$ & 11,8 & 4,2 & 3,14 & 8,6 & 7,1 \\
\hline
\end{tabular}

* e **: significativo a $5 \%$ e $1 \%$, respectivamente.

${ }^{1}$ Valores nas colunas seguidos pela mesma letra não diferem entre si pelo teste de Tukey a $5 \%$

Tabela 2. Número de flores femininas (FF) e masculinas (FM), número de dias até o início da colheita (DC), número de frutos abortados/ planta (FA) e número de frutos comerciáveis/planta $(\mathrm{FC})$ em plantas de pepino com e sem enxertia, usando três métodos: fenda cheia, encostia e perfuração apical. Botucatu, UNESP, 1998.

\begin{tabular}{lccccc}
\hline \multicolumn{1}{c}{ Tratamento } & $\mathbf{F F}^{* *}$ (flores/pl) & $\mathbf{F M}$ (flores/pl) & $\mathbf{D C}^{* *}$ (dias) & FA* (frutos/pl) $^{*}$ & FC (frutos/pl) \\
\hline Fenda cheia & $23,6 \mathrm{ab}$ & $9,6 \mathrm{a}$ & $34,8 \mathrm{~b}$ & $4,0 \mathrm{ab}$ & $12,8 \mathrm{a}$ \\
Encostia & $24,0 \mathrm{ab}$ & $9,4 \mathrm{a}$ & $35,2 \mathrm{~b}$ & $3,8 \mathrm{ab}$ & $13,2 \mathrm{a}$ \\
Perfur. apical & $25,0 \mathrm{a}$ & $9,2 \mathrm{a}$ & $35,6 \mathrm{~b}$ & $4,4 \mathrm{a}$ & $12,0 \mathrm{a}$ \\
Pé franco & $22,0 \mathrm{~b}$ & $9,4 \mathrm{a}$ & $39,2 \mathrm{a}$ & $3,0 \mathrm{~b}$ & $11,0 \mathrm{a}$ \\
Média & 23,6 & 9,4 & 36,2 & 3,8 & 12,1 \\
\hline CV $(\%)$ & 4,6 & 15,2 & 1,7 & 19,1 & 12,4 \\
\hline
\end{tabular}

* e **: significativo a $5 \%$ e $1 \%$, respectivamente.

${ }^{1}$ Valores nas colunas seguidos pela mesma letra não diferem entre si pelo teste de Tukey a $5 \%$

No método da perfuração apical utilizou-se arame grosso, de $0,4 \mathrm{~cm}$ de diâmetro com a ponta aplainada, e com este foi feito um orifício no ápice da abóbora entre as folhas cotiledonares, de aproximadamente $0,5 \mathrm{~cm}$ de profundidade (Figura 3). No hipocótilo do pepino foi feito um corte em forma de bisel de aproximadamente $0,5 \mathrm{~cm}$ abaixo dos cotilédones e introduzido no orifício feito entre as folhas cotiledonares da abóbora.

O transplante para vasos de plástico com capacidade para 10 litros ocorreu 10 dias após a enxertia. O substrato foi preparado com Latossolo Vermelho Amarelo, retirado de camada superficial de $20 \mathrm{~cm}$, corrigido para $80 \%$ de saturação de bases com calcário dolomítico e misturado com adubo orgânico na proporção de $10 \%$ do volume total do solo. Este solo foi adubado com $100 \mathrm{mg} \cdot \mathrm{dm}^{-3}$ de fósforo utilizando-se superfosfato simples. O potássio foi elevado para 4,0 $\mathrm{mmol}_{\mathrm{c}} \cdot \mathrm{dm}^{-3}$ utilizando-se nitrato de potássio.

As plantas foram tutoradas individualmente e conduzidas em fio vertical. A irrigação foi feita pelo sistema de gotejo na razão de três litros/dia. Foram feitas três adubações de cobertura aplicando-se 2,5 $\mathrm{g} /$ vaso de cloreto de potássio e 1,0 g/vaso de nitarato de amônio em cada aplicação.

Foram avaliados a sobrevivência de plântulas de um total de 50 plantas/parcela, altura das plantas (das folhas cotiledonares até o meristema apical), número de internódios acima das folhas cotiledonares, diâmetro no ponto médio da região da enxertia e no hipocótilo daquelas não enxertadas, número de dias até o início da floração, número de flores femininas e masculinas e número de dias até o início da colheita. Em 5 semanas de colheita contaram-se os números de frutos abortados/planta e comercializáveis/ planta (20 cm de comprimento).

$\mathrm{Na}$ análise de variância, a comparação das médias foi feita pelo teste de Tukey a $5 \%$, para todas as características avaliadas.

\section{RESULTADOS E DISCUSSÃO}

Dentre os métodos, a fenda cheia resultou em maior taxa de sobrevivên- cia e plantas enxertadas pelo método da perfuração apical tiveram menor sobrevivência (Tabela 1). A baixa sobrevivência das mudas enxertadas por perfuração apical, pode ter sido influenciada pela pouca experiência do enxertador com esta técnica. Portanto é precipitado afirmar-se que o uso desse método acarreta grande perda de plântulas enxertadas. De forma geral, a taxa de sobrevivência obtida foi bastante baixa se comparada com dados obtidos por Stripari et al. (1997) que obtiveram valores entre 96,5 e $100,0 \%$ aos 25 dias pós enxertia, usando o método de fenda cheia. Isto pode ter ocorrido, possivelmente pela alta temperatura do interior da câmara na pós-enxertia, que ultrapassou $40^{\circ} \mathrm{C}$ no presente ensaio.

A altura das plantas enxertadas não diferiu daquelas não enxertadas. Porém, houve diferenças em relação ao número de internódios/planta. Plantas enxertadas por fenda cheia e por encostia não diferiram entre si quanto ao número de internódios (Tabela 1). No presente ensaio os diferentes métodos usados não 
promoveram diferença na altura das plantas, discordando dos resultados obtidos por Cañizares \& Goto (1998) que relataram que as plantas dos pepinos híbridos Ancor e Nikkey enxertadas sobre abóbora foram mais altas que as não enxertadas. Nas hortaliças enxertadas, o vigor da copa pode ser função do portaenxerto utilizado. No presente ensaio o porta-enxerto Excite Ikky não promoveu aumento de vigor na copa do híbrido Hokuho (Janowski \& Skapski, 1985).

As plantas enxertadas apresentaram maior desenvolvimento na região central do enxerto, quando comparadas com o diâmetro do hipocótilo das plantas não enxertadas (Tabela 2). A prática da enxertia independente do método, aumentou o diâmetro na região superior do hipocotilo entre 0,3 e $0,5 \mathrm{~cm}$. Resultados semelhantes foram obtidos por Cañizares (1997). O aumento do diâmetro na região da enxertia é conseqüência da formação do calo resultante do processo de cicatrização normal constituído por células parenquimatosas (Janick, 1966).

Não houve diferença em relação ao número de dias até o florescimento. As plantas floresceram, em média, 24,2 dias após o transplante (Tabela 1). Em relação à floração, as plantas enxertadas por perfuração apical produziram $25 \%$ a mais de flores femininas/planta do que as não enxertadas (Tabela 2). Atingiram a fase de fruto $54 \%$ das flores oriundas de plantas enxertadas por fenda, 55\% por encostia, $48 \%$ por perfuração e $50 \%$ por pé-franco (Figura 4). Estes dados concordam com os obtidos por Takahashi et al. (1982) que obtiveram aumento do número de flores femininas em plantas de pepino enxertadas sobre Sicyos angulatus.

Não houve diferença entre os tratamentos para número de flores masculinas/planta, sendo que a média geral para o caráter avaliado foi de 9,4 flores masculinas/planta, caracterizando as plantas como monóicas (Tabela 2). A expressão sexual da planta não foi modificada pelos métodos de enxertia, apesar dos valores para flores femininas apresentarem diferenças significativas entre tratamentos. A enxertia induziu maior número de flores femininas porém não diminuiu o número de flores masculinas.

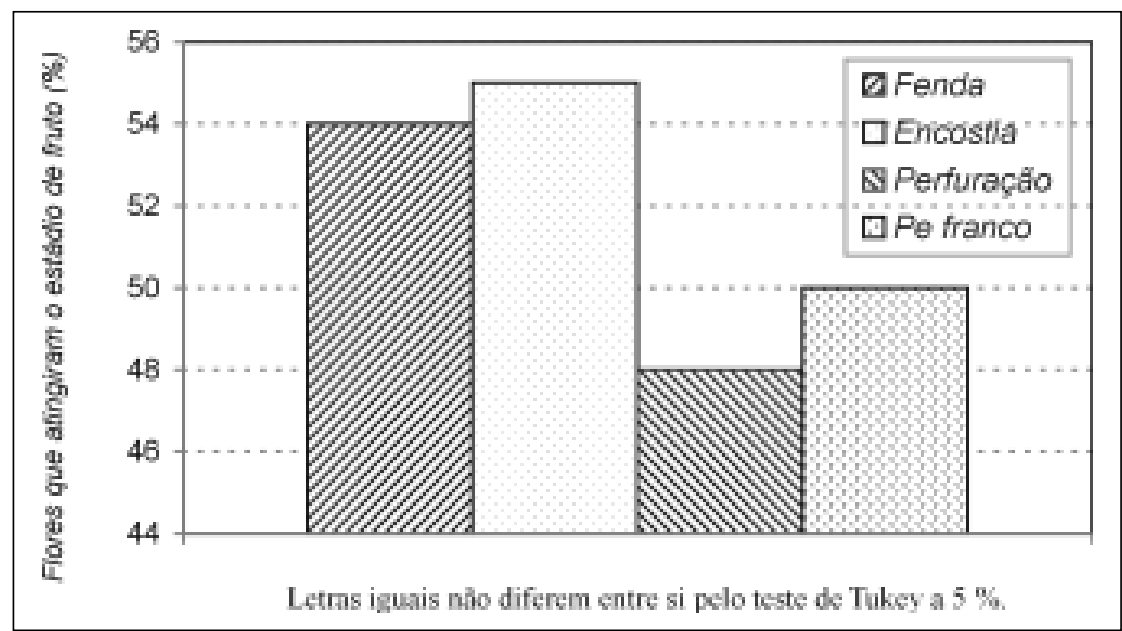

Figura 4. Porcentagem de flores que atingiram o estádio de fruto comercial em plantas de pepino com e sem enxertia, usando os métodos de fenda cheia, encostia e perfuração apical. Botucatu, UNESP, 1998.

Portanto, não houve reversão sexual, discordando de Friedlander et al. (1977) que relataram modificação da expressão sexual em pepino monoico enxertado em porta enxertos ginóicos.

O tempo do plantio até o início da colheita foi superior em plantas não enxertadas que necessitaram em média quatro dias a mais para que os frutos atingissem o ponto comercial de colheita. (Tabela 2). Os resultados obtidos sugerem a existência de efeito positivo da enxertia sobre a precocidade da produção, independentemente do método utilizado.

$\mathrm{O}$ número de frutos abortados foi superior em plantas enxertadas (Tabela 2). Plantas originadas de pés francos apresentaram menor abortamento do que plantas enxertadas por perfuração apical. É possível que o processo de enxertia aliado ao método utilizado tenham provocado estresse inicial que se manifestou na fase de crescimento de frutos, levando ao aborto dos mesmos.

A produção de frutos comercializáveis/planta não diferiu entre tratamentos, em cinco semanas de colheita (Tabela 3). O estresse provocado pela enxertia, não gerou aumento ou diminuição da produção. Entretanto, Yamakawa (1982), Kawaide (1985) e Cañizares (1997) obtiveram maior produção.

Quanto à qualidade visual, todos os frutos produzidos pelas plantas enxertadas apresentaram casca brilhante. Nos frutos de plantas não enxertadas obser- vou-se a presença de cera na casca, de acordo a observações feitas por Yamakawa (1982), Fujieda (1986) e Cañizares (1998).

Sob condições de manejo do presente experimento, conclui-se que, plantas obtidas pelo método de garfagem em fenda cheia apresentaram maior sobrevivência, quando comparado aos outros métodos testados. Os métodos não influenciaram na altura das plantas, porém o diâmetro do hipocótilo foi maior nas plantas enxertadas. Os métodos testados não tiveram influência sobre a produção comercial de frutos em cinco semanas de colheita, porém a enxertia, independente da metodologia utilizada, antecipou a colheita em 3 dias aproximadamente. Todos os pepinos colhidos das plantas enxertadas apresentaram brilho na casca, característica importante do ponto de vista comercial.

\section{AGRADECIMENTOS}

À Fundação de Amparo à Pesquisa do Estado de São Paulo (FAPESP).

\section{LITERATURA CITADA}

ANDREWS, P.K.; MARQUEZ, C.A. Graft Incompatibility. In: JANICK, J. Horticultural Reviews, v. 15, Purdue University, John Wiley \& Sons, Inc. s/d. p. 183-232.

CAÑIZARES, K.A.L. Efeito da enxertia de híbridos de pepino (Cucumis sativus L.) em dois híbridos de abóbora (Cucurbita sp.) sob ambiente protegido. Botucatu, UNESP, 1997. 80 p. (Tese Mestrado). 
CAÑIZARES, K.A.L.; GOTO, R. Crescimento e produção de híbridos de pepino em função da enxertia. Horticultura Brasileira, Brasília, v. 16, n. 2, p. 110-13, 1998.

CAÑIZARES, K.A.L.; IOZI, R.N.; STRIPARI, P.C.; GOTO, R. Enxertado, japonês fica mais brilhante. Agrianual 97. Anuário Estatístico da Agricultura Brasileira. São Paulo, FNP, Consultoria \& Comércio, 1996. p. 332-333.

FRIEDLANDER, D., ATSMON, D., GALUN, E. The effect of grafting on sex expression in cucumber. Plant Soil, v. 18, p. 1343-1350, 1977. FUJIEDA, K. Cucumber. In: KONISHI, K.; IWAHORI, S.; KITAGAWA, H.; YAKUWA, T. Horticulture in Japan. Tokio, Asakura Publishing Co., Ltda., 1986. 180 p.

JANICK, J. A ciência da horticultura. Rio de Janeiro: Freitas Bastos, 1966. p. 224-329.

JANOWSKI, G.; SKAPSKI, H. Hydro-peat method for greenhouse cucumber production. Acta Horticulturae, Wageningen, v. 156, p. 27-33, 1985.
KAWAIDE, T. Utilization of rootstocks in cucurbits production in Japan. Japanese Agricultural Research Quaterly, Tokio, v. 18, n. 4, p. 285-288, 1985

MIGUEL, A. Injerto en hortalizas. Generalitat Valenciana, Conselleria de Agricultura, pesca y alimentación, 1997. 88 p.

ODA, M. New grafting methods for fruit-bearing vegetables in Japan. Japanese Agricultural Research Quaterly, Tokio, v. 29, p. 187-194, 1995. ODA, M.; TSUJI, K.; SASAKI, H. Effect of hypocotyl morphology on survival rate and grow of cucumber seedlings grafted on Cucurbita spp. Japanese Agricultural Research Quaterly, Tokio, v. 26, p. 259-263, 1993.

RACHOW-BRANDT, G.; KOLLMANN, R. Studies on graft unions. IV. Assimilate transport and sieve element restitution in homo and heterografts. Journal Plant Physiology, v. 139, p. 584-589, 1992a.
RACHOW-BRANDT, G.; KOLLMANN, R. Studies on graft unions. V. Unloading of assimilates in homo and heterografts. Journal. Plant Physiology, v. 139, p. 579-583, 1992 b.

STRIPARI, P.C.; IOZI, R.N.; CAÑIZARES, K.A.L.; TRAVASSOS, L.H.; GOTO, R. Influência do intervalo de semeadura na sobrevivência e na qualidade de mudas de pepino enxertado em abóbora. Actas de Horticultura, v. 16, p. 33-37, 1997.

TAKAHASHI, H.; SAITO, T.; SUGE, H. Intergeneric translocation of floral stimulus a graft in monoecious cucurbitaceae with special reference to sex expression of flowers. Plant Soil, v. 23, n. 1, p. 1-9, 1982.

YAMAKAWA, K. Use of rootstocks in Solanaceous fruit-vegetable production in Japan. Japanese Agricultural Research Quaterly, v. 15 , n. 3, p. 175-179, 1982.

MELLO, S.C.; DECHEN, A.R.; MINAMI, K. Influência do boro no desenvolvimento e na composição mineral do pimentão. Horticultura Brasileira, Brasília, v. 20, n. 1, p. 99-102, março 2.002.

\title{
Influência do boro no desenvolvimento e na composição mineral do pimentão ${ }^{1}$.
}

\author{
Simone C. Mello²; Antonio Roque Dechen ${ }^{3}$; Keigo Minami ${ }^{3}$ \\ ${ }^{2}$ Rua das Magnólias, 135, Jd. Novo Mundo, 13.211-610 Jundiaí, SP; ${ }^{3}$ ESALQ, C. Postal 09, 13.418-900 Piracicaba-SP. E-mail: \\ secmello@zaz.com.br
}

\section{RESUMO}

O experimento foi conduzido no município de Piracicaba (SP), de fevereiro a junho de 1994, em solo classificado como Terra Roxa Estruturada eutrófica A moderado textura argilosa. Visou-se estudar a aplicação de boro no desenvolvimento e na composição mineral de plantas de pimentão cv. Magda. Adotou-se o delineamento em blocos casualizados com quatro doses de bórax aplicadas nas covas de plantio $\left(0 ; 5 ; 10\right.$ e $20 \mathrm{~kg} \mathrm{ha}^{-1}$ equivalentes a $0 ; 0,6 ; 1,1$ e $2,2 \mathrm{~kg} \mathrm{ha}$ ${ }^{1}$ de B) e quatro repetições. Avaliou-se a altura das plantas, o número de folhas e de flores, a área foliar, o peso da matéria seca da parte aérea e os teores de nutrientes nas folhas recém-maduras mais pecíolos, aos 45 dias após o transplante. Foram avaliados também, aos 40 dias após o transplante, o peso do material verde dos frutos e a composição mineral do pericarpo e das sementes dos mesmos. As doses de bórax não influenciaram as características avaliadas e os teores de macronutrientes e de $\mathrm{B}, \mathrm{Cu}, \mathrm{Fe}, \mathrm{Mn}$ e $\mathrm{Zn}$ nas folhas mais pecíolos. Entre as partes dos frutos, os teores de B foram superiores nas sementes em relação ao pericarpo, nas quatro doses utilizadas.

\section{ABSTRACT}

Influence of boron application on sweet pepper development and mineral composition.

An experiment was carried out in Piracicaba (Brazil) from February to June 1994, to study the effects of boron application on the development and mineral composition of sweet pepper (Capsicum annuиm L.), cultivar Magda. The experiment was carried out in a randomized block design with four levels of borax $(0 ; 5 ; 10$ and $20 \mathrm{~kg}$ ha ${ }^{-1}$ equivalent to $0 ; 0.6 ; 1.1$ and $2.2 \mathrm{~kg} \mathrm{ha}^{-1}$ of B) and four replications. The plant height, number of leaves and flowers were evaluated, also the foliar area, dry weight of aerial part and nutrient contents in the leaves plus petioles at 45 days after transplanting date. In addition, fruit fresh weight; pericarp and seed mineral composition were evaluated 40 days after transplanting date. Different concentrations of borax did not affect the evaluated characteristics nor the macronutrient and $\mathrm{B}, \mathrm{Cu}, \mathrm{Fe}, \mathrm{Mn}$ and $\mathrm{Zn}$ levels in the leaves plus petioles and fruits. For the pericarp and seeds, the concentrations of boron were higher in the seeds than of in petioles for all levels of applied borax.

Palavras-chave: Capsicum annuum, boro, bórax, nutrição mineral.

Keywords: Capsicum annuum, boron, borax, mineral nutrition.

\section{(Aceito para publicação em 27 de novembro de 2.001)}

$\mathrm{O}$ pimentão (Capsicum annuum L.), apesar de sua reconhecida importância econômica, é pouco estudado no Brasil, no que diz respeito à adubação com micronutrientes, especialmente o boro. Além de afetar o desenvolvimento e a produção do pimentão, o boro pode interferir no equilíbrio nutricional da cultura. Segundo Correia et al. (1977), a deficiência de B em plantas de pimentão reduz o peso do material seco da parte aérea e das raízes, o nú-

\footnotetext{
${ }^{1}$ Parte da dissertação de mestrado apresentada pelo primeiro autor à ESALQ/USP.
} 